\title{
Ways of seeing: Biomedical perspectives on the social world
}

\author{
Charlotte Humphrey
}

J R Soc Med 2006;99:602-606

In the UK health arena it has become axiomatic that, despite medicine's great achievements in the past, a biomedical perspective is no longer adequate on its own. Multidisciplinarity is increasingly regarded as a prerequisite for effective health-care education, practice, policy and research, and a plethora of initiatives exists in all these areas: common learning programmes for health professionals; flexible roles in patient-centred teams; patient participation in NHS decision-making and an increasing emphasis on interdisciplinary research.

Some of these developments have led to real change. Often though, despite the rhetoric, other stakeholders are accommodated by medicine just so far as they are compatible with biomedical values and help solve problems defined in those terms. So, for example, nurses develop extended roles, but only to do things doctors wish to give up. The Expert Patient programme trains people with chronic illness to self-manage, but always within an explicitly medical framework. ${ }^{1}$ Social science research methods are increasingly accepted, but as adjuncts, not alternatives, to randomized controlled trials. ${ }^{2}$

While not discounting these analyses, my purpose here is to suggest there is a further element in play, lying right at the heart of biomedical understanding of the world, which blocks medicine's appreciation both of its own biases and the possible legitimacy of other points of view. I refer, literally, to 'ways of seeing' and the metaphors used for 'picturing' the world.

Metaphors aid understanding, and are most effective when they associate an abstract idea with something more concrete. But the very familiarity that makes a metaphor useful can also distort what it illuminates. A good example is the widespread use of machine metaphors to conceptualize the workings of the biological and social world, which were originally developed by the self-styled 'mechanical philosophers' of the 17th Century. In medicine, the damaging consequences of this reductivist mode of thinking, which privileges technical solutions, depersonalizes patients

Professor of Health Care Evaluation, King's College London, Division of Health and Social Care Research, 5th Floor, Waterloo Bridge Wing, 150 Stamford Street, London SE1 9NH and neglects both social and psychological dimensions of illness, are now well recognized.

The use of visual metaphors is less remarked upon, but arguably just as powerful in structuring our ideas. We routinely rely on visual metaphors to conceptualize our thought and understanding. Thus, we 'observe, reflect, envisage'. You 'see what I mean'. I have 'insight', you have 'foresight'. And everyone has their 'point of view'. The primacy accorded to visuality over other sensory modes can be illustrated by considering the greater status afforded it in law. ${ }^{3}$ Eyewitnesses are preferred over ear-witnesses, whose 'hearsay' may be inadmissable. Nuisance plaintiffs demonstrating harm from soot or smoke do better than those complaining about noise or smells. In defamation law, printed libel is more serious than oral slander. In negligence law, visible injury rates more compensation than invisible emotional distress.

But the visual mode has not always dominated. In preliterate societies, knowing was linked not to seeing, but to hearing. Early mediaeval wise men were those who 'heard well', and knowledge was gained and shared through storytelling. The rise in respect for the visual reflects the growth of literacy, which was accelerated by the invention of the printing press.

In the 17th century, the emphasis on vision was much reinforced by the same early scientists who bequeathed us the machine model. Knowledge gained through sight was particularly compatible with the Enlightenment view of the world, because of the way that seeing detaches the viewer from what they observe, as Durer's etching, The Artist at Work, makes clear (Figure 1). Looking emphasises objectivity. When looking at people, what they are may be separated from who they are and what they think. The science of the Enlightenment stressed the physical and material qualities of matter, rejecting the traditional animist philosophy that attributed intentions and soul-like properties to natural objects, such that flames rose and stones fell, each striving to achieve its proper position in the world. The new 'natural philosophers' stressed the importance of facts obtained through direct empirical observation and eschewed the authority of inherited orthodoxy. And much of the knowledge of the new science depended on optical instruments - the microscope and telescope-to learn about things too small or far away to be visible without them. 


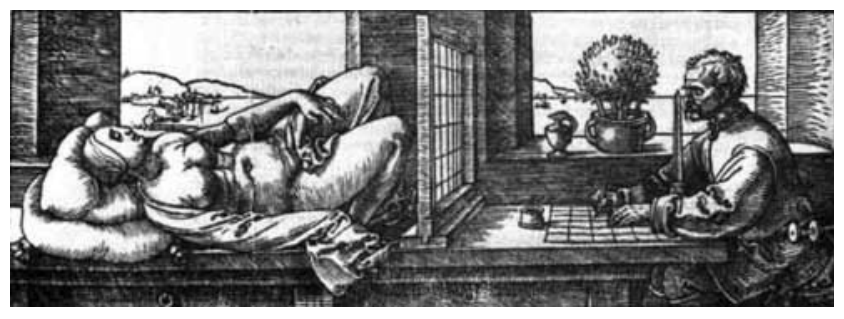

Figure 1 Durer's etching, The Artist at Work

My contention is that when medicine adopted the science of the Enlightenment as its knowledge base, it also adopted the visual bias of its mental map. This included not just the emphasis on learning by looking, but also the conventions established by then in Western art for 'picturing' the world through geometric linear perspective - the focus on a single vanishing point to which all parallel lines converge, which enables the accurate representation of three-dimensional space on a flat plane, as demonstrated in de la Francesca's Portrait of an Ideal City (Figure 2). This approach, first developed in Italy in the 1400 s, was subsequently adopted across Europe, such that by the 17 th century it had become the norm.

How do the conventions of linear perspective influence what is seen? In non-perspective painting, as exemplified in Memling's Passion of Christ (Figure 3), everything that matters and all moments in a narrative can be included, showing whatever is necessary to represent the intended subject.

In contrast, 'natural perspective', as it came to be called, is much more limiting. Pictures are framed from a particular point of view. Objects are included only to the extent that they are literally visible from the viewpoint of the person who selects the frame. In this sense, perspective is tyrannically definitive, concentrating attention on what is included, not what is left outside or how the choice was made. As Berger has observed:

'The convention of perspective centres everything on the eye of the beholder. It is like a beam from a lighthouseonly instead of light traveling outwards, appearances travel in. The conventions call those appearances reality.
Perspective makes the single eye the centre of the visible world. The visible world is arranged for the spectator as the universe was once thought to be arranged for God. The inherent contradiction in perspective is that it structures all images of reality to address a single spectator who, unlike God, can only be in one place at a time.' ${ }^{4}$

In natural perspective space becomes unified, continuous and neutral. The appearance of objects reflects their physical characteristics and position rather than symbolic meaning or relationships. Moreover, the naturalistic frame selects and fixes a particular moment. The simultaneous representation of past or future events becomes unfeasible, so the focus is always on a static present. And, since perspective creates apparently realistic depth, it supports the illusion that what is shown really is the world, not just one interpretation. This illusory quality was further enhanced in Renaissance painting by the advent of oil paint, which made texture, lustre and solid form much easier to depict convincingly.

Returning to the present, my contention is that medicine's understanding of the world around it remains, all unwittingly, influenced by these conventions. This can be illustrated by briefly describing a project that took place a few years ago. ${ }^{5}$

The aim of the project was to ensure that clinical policy in certain areas of care in three local obstetric units was consistent with the best evidence available. The idea for the initiative came from a doctor passionately committed to the principles of evidence-based medicine. The project was sponsored by the health authority and led by the local Maternity Services Liaison Committee (MSLC). The plan involved identifying obstetric interventions for which good evidence existed, exploring unit policies relating to those interventions, comparing the policies with the evidence and, where differences were found, agreeing actions to bring them into line. The impact of the project was assessed by an independent evaluation team, which tracked its progress by observing at meetings and interviewing all stakeholders. It was agreed that the evaluation findings would not be shared with the project leaders until the project was completed.

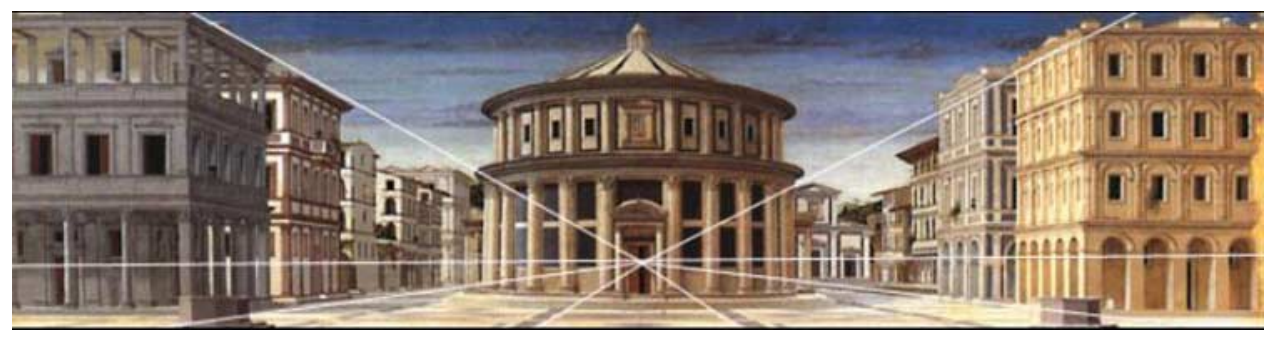




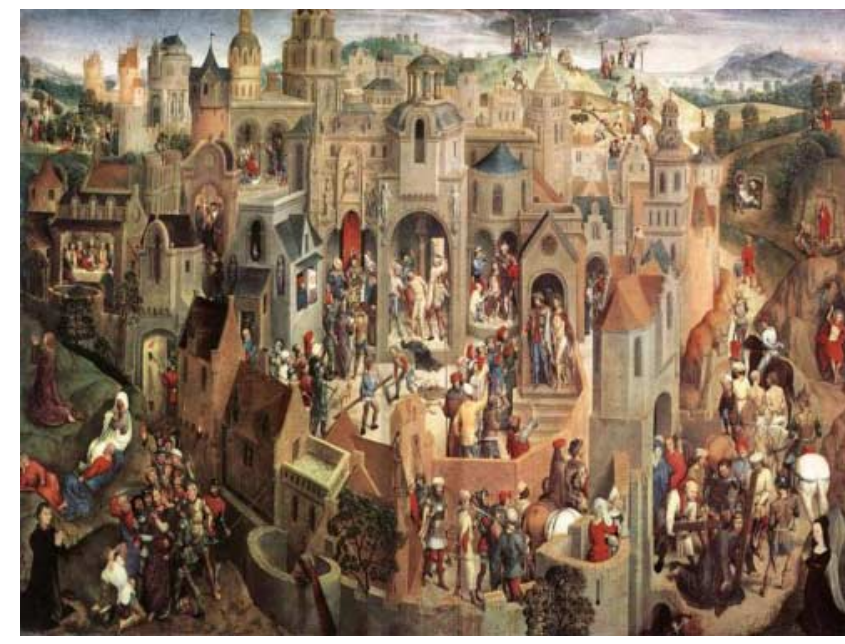

Figure 3 Memling's Passion of Christ. In colour online

The project leaders chose four interventions from the Cochrane Pregnancy and Childbirth Database ${ }^{6}$ and held meetings to discuss each intervention with each unit. Of the twelve unit policies investigated, seven were found to be consistent with the research evidence, while in five cases major discrepancies were identified. Subsequently, two of the discrepant polices were revised to match the evidence.

The project was celebrated by its proponents as a great success, on the basis that all units cooperated fully throughout, constructive discussions were held and two of the five deviant policies were subsequently corrected. The approach was presented at a conference as an exemplary model of cooperative working. To adapt Berger's analogy, the beam from the lighthouse appeared to be shining steadily (Figure 4).

But, as in this photo, the light was an illusion. Alter the viewing point a little, and what is actually reflected sunlight disappears. For the evaluation findings told a rather different story. Unit staff were highly critical of the initiative, seeing its priorities as misguided and its processes unhelpful. Even where policies had been changed, the influence of the project was disputed, revisions being attributed rather to shifts in thinking occurring at that time among obstetricians round the country.

When these negative views were revealed to the project leaders, they reacted with surprise and considerable disappointment. So why had they not realized how the unit staff felt? The answer lies in their framing of the problem they hoped to address and the assumptions this reflected: that variable practice was necessarily a bad thing; that non-compliance with 'evidence' must reflect a deficit of knowledge or skills; that the solution was therefore to provide information and support; and that this would be acceptable to the units if delivered by a suitably neutral agency such as the MSLC.
Unfortunately, these assumptions were not shared by unit staff. In their view, variation between units was not necessarily a problem but might rather be a legitimate means of meeting patient need and offering choice; it was not that they did not understand the evidence, but that sometimes it conflicted with other relevant knowledge, such as clinical experience in the local context; so they wanted neither information nor support, but the opportunity to present alternative arguments; and the MSLC was seen as neither neutral nor constructive, but as an agent of the health authority with a history of causing them trouble and extra work.

As it happens, the project leaders had realized that unit staff might be sensitive to outsiders coming in and telling them what to do, but the steps they took to deal with this were insufficient. They defined the object of gaze in their own terms and then, figuratively speaking, walked round it to see how it might look from the units' point of view. Since they took their own assumptions with them, still intact, all they saw was what 'made sense' to them. They did not, or perhaps could not, imagine themselves in the shoes of the unit staff involved in a project not of their choosing, their own concerns suppressed by the project leaders' decisions about what issues to consider. Nor did they think to look at the wider landscape from this new position, to see what other considerations now entered the picture (unit patients, professional colleagues, wider trust interests, other commissioners of care) that might affect how unit staff felt about the project. And they did not consider how past experience or future plans might influence reactions. So, when staff cooperated with the project, the leaders assumed they were persuaded of its value. In fact, one reason why the units chose to participate without a fuss was that it seemed an easy way to please the

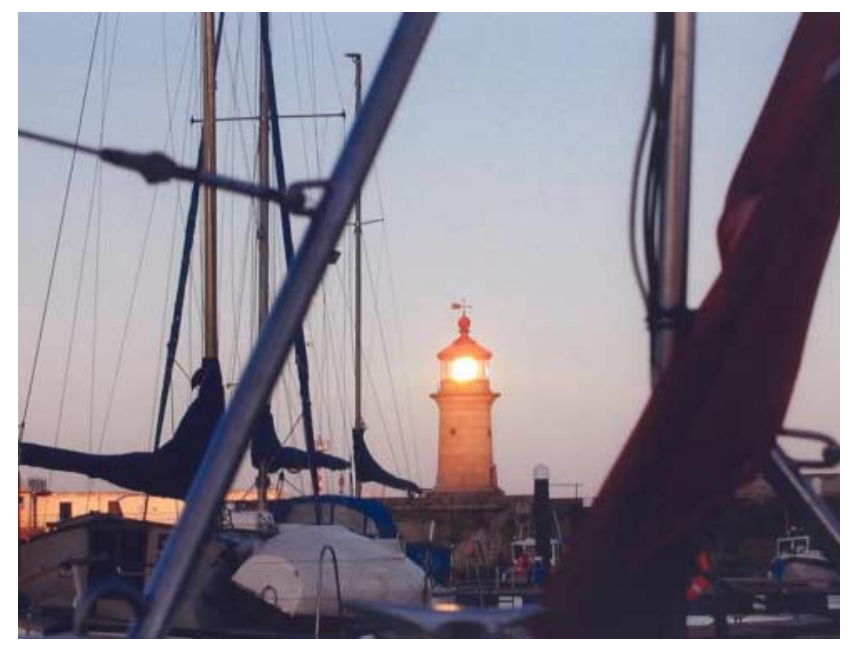

Figure 4 The lighthouse beam. In colour online 
health authority as an investment against other, more important, battles in the future.

These enthusiasts for evidence-based practice were so sure of the rightness of their own viewpoint that they never thought to ask whether unit staff shared it. Nor did they hear when staff told them, on several occasions during the project, that they did not. As a manifestation of one of the most dogmatic elements in contemporary biomedicine, this project is an extreme example. But milder versions of such selective vision, blinkered by belief in the fundamental rightness of the basic tenets of biomedicine, are widespread. Until it is accepted that the biomedical perspective, despite its many strengths, is inevitably both partial and incomplete, genuine appreciation of other views - including those of patients - is unlikely, even when sometimes these may have a greater claim.

How might such recognition come about? In painting, the mimetic traditions of 'academic' realism have long since lost their taken-for-granted status and are now recognized as neither neutral, natural, nor the only way of representing reality. They have been challenged, for example, by critics such as John Berger in his groundbreaking 1973 book Ways of Seeing, which drew attention to the cultural rather than aesthetic content of the images. ${ }^{4}$ For example, in Holbein's painting, The Ambassadors, Berger points out how every item in the frame shows evidence of the labour undertaken by weavers, embroiderers, carpet-makers, goldsmiths, leatherworkers, furriers and tailors to produce fine objects. He suggests that the value of oil painting lay in its power to demonstrate, in all its tactile immediacy, the desirability of what money could buy in the new mercantile culture of that time.

More recently, the artist David Hockney has adduced a volume of evidence from looking carefully at the way pictures were painted to mount a convincing argument that many of the conventions traditionally regarded as artistic inspiration, such as the use of chiaroscuro - bright lights and dark shadows - are actually technical consequences of the discreet use by painters of optic lenses in the form of the camera lucida to produce virtual images of their subjects on the canvas, which could then be accurately traced. ${ }^{7}$ Hockney's discovery put paid to decades of celebratory critical analysis. For example, John Canaday, art critic of the New York Times, enthused about the use of light in Caravaggio's painting the Conversion of St Paul, describing it as 'a symbol of spiritual transfiguration'. ${ }^{8}$ The fact that the light source comes from outside, and is visible only to Saul, is seen by Canaday as evidence of its miraculous nature. After Hockney, we now know that the light is bound to come from outside, because that is a requirement of the optical technique.

And, of course, painters themselves have challenged the realist tradition in a wave of movements from the
Impressionists onwards, who offended the academic establishment by challenging conventional assumptions about colour - that grass was brown and shadows blackand celebrating ephemeral effects of light, rather than the solidity of objects. The Cubists rejected the single viewpoint, exploring how all sides of the object could be represented together. The Italian Futurists rejected stasis, in favour of speed, movement and the passing of time, and the Expressionists focused on the representation of subjective meaning.

The paradigm shift in painting was arguably hastened by the arrival of photography, which completed the illusionist project and forced artists to look elsewhere. For medicine there are new challenges too, which are already leading to a reappraisal. First, scientific understanding itself has changed profoundly. Over the past century, research in many areas - physics, cosmology, population biology and neuroscience - has challenged the 'Newtonian' view of the universe. Ways of thinking about science in terms of models based on clockwork mechanisms, universality and stability, have been replaced by new perspectives that are biologically inspired, probabilistic and dynamic.

Second, the dominance of visual values is being undermined in society at large by a plethora of new technologies for leisure and communication that engage participants through both sight and sound. ${ }^{3}$ Increasing attention is being given to cultural activities that do not depend on written texts and that privilege understanding over abstract, analytic knowledge. Metaphors are altering to match. We 'sound people out', I 'hear what you say'. Consultation processes are 'giving voice' to previously unheard groups. In medicine there is a growing interest in patients' narrative accounts of their illness as a rich resource for understanding quite different from that provided by the traditional examination or formal case history. ${ }^{9}$

In a 1976 paper, Jewson described how medicine has altered over time. ${ }^{10} \mathrm{He}$ identified three successive phases: bedside medicine, when doctors' main resource was listening to their patients; hospital medicine, when they listened less and examined patients for physical signs and symptoms; and laboratory medicine, when the focus was hardly on the patient at all, but on the results of laboratory tests. In the $21 \mathrm{st}$ century, things have moved on yet again. Nettleton has dubbed the latest era 'e-scaped medicine', pointing out that medical knowledge is no longer exclusive to the medical academy, having 'escaped' into the networked spaces of the Internet, where it can be accessed, assessed and appropriated by anyone. ${ }^{11}$

In a lecture at the opening of the UK's newest medical school, the editor of the British Medical Journal argued that 'industrial age medicine' is over, and old practices must give way to new ways of working where doctors cooperate 
with patients as their partners. ${ }^{12}$ Perhaps this latest transformation will include appreciation of a point that is often quite obvious to those on the receiving end of observation. To quote one artist's' model:

'That is the Great Truth that I now understand. In a group of ten people drawing me, I could show you ten different ways of seeing. Some of them will find me attractive, pleasing, and some most definitely not, and each individual will assume that whatever qualities they find are inherent in me. What I clearly understand now, is that what they see has nothing to do with me at all, and everything to do with them. ${ }^{13}$

Potentially there is a lot to learn from others in the drawing group and, above all, from the model herself.

\section{REFERENCES}

1 Department of Health. The Expert Patient: A New Approach to Chronic Disease Management for the 21st Century. London: Department of Health, 2001

2 Campbell M, Fitzpatrick R, Haines A, et al. Framework for design and evaluation of complex interventions to improve health. BMJ 2000;321:694-696
3 Hibbitts JB. Making sense of metaphors. Visuality, aurality and the reconfiguration of American legal discourse. Cardozo Law Review 1994; 229. Reprinted at http://www.law.pitt.edu/hibbitts/meta_int.htm (Accessed 28 September 2006.)

4 Berger J. Ways of Seeing. London: Penguin Books Ltd, 1973

5 Humphrey C, Berrow D. In the eye of the beholder: Problems of perception in designing a strategy to promote evidence-based clinical policy. J Eval Clin Pract, 2000;6:165-76.

6 Neilson JP, Crowther CA, Hodnett ED, Hofmeyer GJ, Keirse MJ, Daley L, (eds) Pregnancy and Childbirth Module, Cochrane Database of Systematic Reviews. Cochrane updates on disk. Oxford: Update Software Ltd, 1995

7 Hockney D. Secret Knowledge. London: Thames \& Hudson Ltd, 2001

8 Canaday J. What is Art? London: Hutchinson \& Co Ltd, 1980

9 Greenhalgh T, Hurwitz B. Narrative based medicine: why study narrative. BMJ 1999;318:48-50

10 Jewson $\mathrm{N}$. The disappearance of the sick man from medical cosmology 1770-1870. Sociology 1976;10:225-44

11 Nettleton S. The emergence of e-scaped medicine? Sociology 2004;38:661-79

12 Smith R. Thoughts for new medical students at a new medical school. BMJ 2003;327:1430-3

13 Wassenberg A. Artist modeling is more than meets the eye. Hamilton \& Region Arts Council website: http://www.harac.on.ca/ abartmod.html 2003 (Accessed 7 October 2003) 